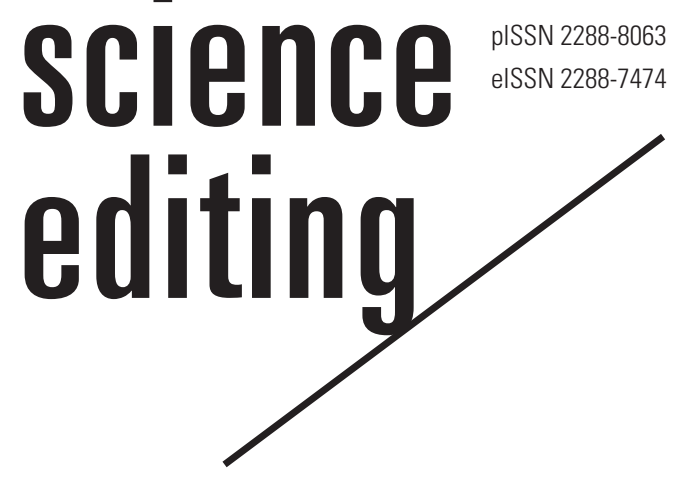

\title{
Language policy and the disengagement of the international academic elite
}

\author{
John Harbord \\ Department of Literature and Art, Maastricht University, Maastricht, Netherlands
}

\section{Abstract}

This paper explores the phenomena of academic multiliteracy (the habit of writing academically in more than one language) and of L2 monoliteracy (that of only writing academically in a language that is not one's own) and their impact on policy. Based on interviews and surveys conducted with 33 multiliterate and 15 L2 monoliterate scholars connected to one university in Central Europe between 2010 and 2014, I show how incentives to publish in English constructed by educational policies often push ambitious young researchers whose first language is not English away from engaging in academic and societal debates in their first language community. They may thus disengage from the national community, with negative consequences for the interaction between global and local that is essential for good governance. To overcome the difficulty young scholars encounter in writing in their native languages, they should be taught writing both in their native language and in English. Furthermore, university and state policies should reward scholars for writing not only for the international community but also for local society.

Keywords

Language; Motivation; Publishing; Research personnel; Reward

Received: September 22, 2017

Accepted: January 19, 2018

Correspondence to John Harbord jr.harbord@maastrichtuniversity.nl

ORCID

John Harbord

https://orcid.org/0000-0002-8011-7676

This is a truncated secondary publication of the book chapter 'Language policy and the disengagement of the international academic elite,' originally published in Curry MJ, Lillis T, editors. Global academic publishing: policies, practices, and pedagogies. Multilingual matters: Bristol, UK; 2017, permitted by the publisher.

\section{Introduction}

Not so very long ago, Huntington [1] summarily dismissed the argument that English is "the world's language." A language that is foreign to $92 \%$ of the world's population, he pointed out, cannot in the most basic sense be the world's language. The extensive research published-in English - on the role of English as the global language of academe occasionally overlooks this fact. In the field of governance, Huntington notes, there exists an English-speaking elite of key actors from almost every country in the world that shares cultural values related to "individualism, market economies, and political democracy," which he names The Davos Culture. The globally mobile non-Western members of this elite co-exist or, better, "super-exist" with the people of their own countries, who live on a day-to-day basis according to often quite different canons of values. While this tiny minority wields enormous power, it is in no way representa- 
tive of the vast majority of the world's population, either culturally, or linguistically.

Similar concerns about the isolation and unrepresentativeness of an English-speaking international academic elite drive this article. Scholarship has addressed the difficulties of publishing in English as a second language [2,3], the skewing of power relations in favor of English native speakers in the Anglophone center [4], and measures that might affect them [5]. Simultaneously, another strand of discourse has addressed the concern that scholars do not engage sufficiently with the world beyond academe [6,7]. And in a world where the vast majority of the population still either cannot effectively or do not normally operate in English, publications in English have limited impact [6]. Despite the importance of supranational bodies such as the European Union, many key policy debates continue to be resolved at national level, and in national language [8].

Seeking to strengthen institutional research profiles, universities and higher education ministries are increasingly introducing policies that encourage or pressure scholars to publish in English [3,9-12]. While these may or may not have positive effects on academic publishing choices within national systems [10], their impact on the interaction between academe and society has yet to be seriously studied.

The purpose of the present study was to investigate the multiliterate publishing activities of a group of scholars in the social sciences and humanities connected to a US-accredited international university and to examine how the interaction of their career paths and external factors influences what they publish and with what consequences. Specifically, I show how they perform two distinct types of writing behavior: many write in English for an elite international academic community to share new cutting-edge knowledge and in their first language for groups for the national linguistic community, to share, apply, and adapt knowledge that is new for those who do not belong to the international academic community. Policies rewarding publishing only in English often work against those who seek to play this bridging role, favoring those who disengage from the local in favor of the international elite. Maintaining and valorizing this dual role is crucially important to prevent a split between the international global academic elite and local national communities. Appropriate policies, I suggest, can support this role, with positive consequences for governance.

\section{Methods}

In the present study, I gathered data from two groups of researchers who have either studied or work at a private, international US-accredited English-medium university in Central
Europe, with students and faculty from many countries. All informants are fluent in English (International English Language Testing System estimated 8.0 or above) but do not identify it as their first language. All publish in English, but not all in their first language. I refer to the publishing behavior of those who write in English and any other language (s) as multiliterate, and of those who write exclusively in English as a second (or other) language as L2 monoliterate. I also choose the latter term based on participants' statements of their perceived inability or refusal to write in their first language. This "inability" will form a key focus of discussion below.

The first set of data is from semi-structured interviews (Appendix 1) I conducted with 15 research faculty (8 men and 7 women aged between their mid-thirties and late fifties) and $18 \mathrm{PhD}$ students (8 men and 10 women in their late twenties and thirties) from 12 disciplines in the humanities and social sciences, with 13 different first languages, none of them English (group A). Of the total participants, 12, including most faculty members, publish in two or more languages; 21, including most PhD students, publish only in English. Three participants were native speakers of super-central [8] languages (German, Turkish, and Russian); others spoke Czech, Croatian, Dutch, Hungarian, Italian, Lithuanian, Norwegian, Polish, Romanian, Serbian, and Slovak. Further data was gathered via questionnaires (Appendix 2) completed in English by 15 alumni of the university under the age of 40 (slightly more women than men), whose first languages include Albanian, Bangla, Bosnian, Czech, Hungarian, Lithuanian, Romanian, Slovak, and Turkish, and who according to their LinkedIn profile are active in research positions (group B). Most publish in English and another language. Groups A and B both contain multiliterate and L2 monoliterate scholars. They are distinguished as A and B because data was gathered during two separate periods using different methods and slightly different sets of questions, as described above. All extracts are presented using conventional written punctuation.

The university under study has for some 14 years had an institutional policy that requires faculty to publish two articles per year in international peer-reviewed journals in English. In one or two disciplines (history and allied fields), publications in German and French may also be accepted. Publications in other national languages are not. It is important to note here that this policy directly affects only the faculty in group A. Those in group B are most influenced by policies in the country or institution where they work, while the $\mathrm{PhD}$ students in group A are likely influenced by anticipated policies in contexts where they plan to work, and they may see the policies of the university where they are presently studying as a typical example [13]. 


\section{Results}

Responses of both groups revealed motivations in line with the existing literature. For them, a key issue is the need to reach a specialized audience who understand their research area. Less influential languages were frequently perceived not to offer an audience worth addressing.

I publish in English to reach a larger audience. Creating a critical mass is only possible at global level. There are too few journals in my mother tongue, much smaller audience. (A1)

You write for a large, highly specialized audience in English. In other languages you can only get an audience that large if you are less specialized, so writing in those languages is less specialized. (A2)

Among group B, similarly, six considered their research area to be of little interest to researchers in their home country; a further (slightly overlapping) six believed that all those from their home country they hoped would read their work would understand English. These scholars are not writing academically for a local audience because in their eyes that audience is often small and speaks English anyway.

Career gains from publishing in English were also a prominent theme. In group B, over two thirds (11) saw no professional benefit from publishing academically in one's own language, although six had on occasion done so. One added:

... publishing in English is not only more convenient for me as a graduate from American (English-speaking) university, but also much more practical and beneficial for my further career as an international researcher. (B5)

Among members of Group A, opinions were similar.

Prestige and rewards of writing in English are much greater. (A3)

I write everything serious in English. I write for pleasure in French. (A1, Hungarian speaker)

Career benefits and the (un)availability of a specialized audience thus tend to mitigate against the motivation to publish in local languages. Indeed, for this group of informants (both groups A and B), whose mastery of English is extremely good and who see themselves as part of an international (Englishspeaking) academic community, publishing in English would seem like a natural choice, while publishing in their first language would likely bring fewer or no career returns.
The one economics journal in Slovak is ranked 185th in the world. I try not to publish there (A2).

Thus for an established academic, where academic publishing in national languages means publishing in low-ranked journals, it may actually be detrimental to one's career to do so.

\section{Career mobility and disengagement}

Other factors further discourage local-language publishing, particularly among younger researchers. The tendency among the young scholars in this study to publish mostly or exclusively in English may be due to their context of a high-ranking, highly international research-intensive university. The $\mathrm{PhD}$ students and alumni are mostly not working in their country of origin, and many were also not tied to the country where they were when the research was carried out. For them, Poland, Turkey or Russia may offer less promising career prospects and a lower standard of living than, for example, the United States or the western states of the European Union. Of those in group B, many were not in their country of origin, several being employed in English-speaking countries; several said they do not seek a link with their 'home community' either because they are 'not interested' or have simply lost contact.

I started [working in a research position] in Switzerland, then moved to Germany, now I am in Denmark. I no longer have much scholarly connection to Romania. (B1)

I am rather poorly connected with the Slovak academic environment. I do not find it inspiring, but I also lack good local academic networks due to my studies abroad. (B2)

The career path of these students, as the first example above clearly shows, predisposes them to become part of a relatively mobile international research community. While one $\mathrm{PhD}$ student (A13) did consider herself living in a "little English world" cut off from her first language community, more typically, national communities themselves were described as closed off from "where it's at" academically (A7), due to their choice of language, and identified as "older" (A7, A8). This is in contrast to findings by Anderson [13] that western European academics see publication in multiple super-central European languages as a ticket to career mobility, and more akin to Duszak's account of "English [as] a key to a 'better' world" in pre-1989 Poland [14].

The second consequence of mobility is the construction of a global academic elite as a monolingual transnational community held together by a language which is frequently not that of its members, but which, for reasons discussed below, becomes the only language they feel academically comfort- 
able in. While the difficulties of publishing in English have been much discussed, less attention has been paid to how much easier it can be to write in English than in most other languages, ceteris paribus. Many of the younger scholars mentioned feeling uncomfortable or awkward writing in their first language, particularly as regards terminology for which local equivalents either do not exist or are not known.

Writing in Czech would be substantially more time consuming and demanding. (A3)

I use English to write scholarly papers because the technical jargon does not exist in Slovak. It is simply easier to use English. When I use a certain English term, everybody knows what I am talking about. (B1)

In my native language it takes more time to find the suitable terms. (A14)

Several identified more demanding expectations in other language communities than in English: that they have higher stylistic expectations than English audiences. Non-English audiences, they claim, are linguistically much more unforgiving, and in many languages, stylistic complexity and tour de force is welcomed because it is assumed that all users of that language will be highly proficient, and that performing such rhetorical feats is a part of national culture [15]. This linguistic expertise usually takes effort to acquire, however. One senior scholar commented that she chose not to publish in Hungarian journals in spite of her fluent command of the language.

They really expect you to produce a very complex, ornate style, and they criticize you if you don't do it. It is the same actually in German but there it's not a problem for me as I've been doing it my whole academic career. (A9)

The fact that simplicity is perceived as more desirable in English thus meshes well with many writers' perception of their own linguistic abilities. In contrast, for those who have little practice and limited motivation, writing in the complex style they perceive as necessary in their first language represents an obstacle. Several found writing in English liberating, or else as constraining one to keep to the point.

Writing in Hungarian is a more painstaking process for me... I feel like I write more freely in English. (B7)

It is easy for me to write a long paragraph that says nothing in Slovak. My English is not good enough to do that. (A2)

It is also not surprising, given that English is one of the few languages in which students from most European countries are explicitly taught to write at all beyond high-school composition [15]. Almost all the younger scholars I interviewed had received writing courses, and many commented that this had strengthened their confidence in writing in English. Very few had received guidance in how to write in their first language.

Since, the first time I learned how to conduct research, and how to structure a paper, and write it down, I learned it in English. Therefore, in my professional career I find it much easier to write and communicate in English rather than $\mathrm{Al}$ banian. (B3)

Yes, I find expressing myself in English easier. This might be related to the fact that my MA and $\mathrm{PhD}$ education was in English and I learned to structure texts and arguments in this language and not in my mother tongue. (B2)

This finding is in line with Anderson's [13] findings that the language of the $\mathrm{PhD}$ thesis is a key indicator for subsequent publishing choices.

\section{Why does first language writing matter?}

Several among my informants, especially the more senior, do write in their first language, in spite of the negligible career returns. However, scholarly articles are not their typical products; indeed many do not write such articles in their first language at all. A number mentioned that writing in their first language is sometimes not a deliberate choice but a response to an invitation or a request. These include policy-related documents - the older scholars typically acting as government advisors (A1, A7, A10, A11, A12), whereas the younger ones more often do so for non-governmental organizations (NGOs) (A8, B2) - giving conference plenaries, or writing texts for a broad intellectual non-specialist audience reachable through high quality daily newspapers, intellectual magazines on socio-political themes, and so on.

I write for less scholarly audiences in Serbian, e.g. teachers. (A11)

When I write in English I am writing at the top of the market. I write in German at various levels. (A9)

Several faculty members in the first group also write textbooks for university students. Three members of the second group had published educational materials in their first language, none in English, an educational role which, while it may not create new knowledge, is undoubtedly of intrinsic value. In general, like scholars mentioned by Duszak and Lewkowicz [15] and Lillis and Curry [4], both groups interviewed in this study do engage or wish to engage with the 
wider community—often with social goals:

When I write in Turkish I write for academics and NGO activists, therefore I feel free to combine academic discourse with everyday language. If it is not for an NGO I write in English. (A8)

I write my academic articles in English to reach international academia and public and I write Bangla articles and popular columns, to reach the most common people in my country. Specially, writing in Bangla helps students to understand critical debates more easily. (B6)

I feel if I had training in writing in Croatian, I would be doing it. I would like to address the local audience and bring things to them... Academics should be partners in a dialogue to produce knowledge that has a social effect. (A13). It is important to keep writing in Lithuanian. To drop it would be somehow degrading. Students should be taught in both languages. (A14)

\section{Discussion}

This study has sought to understand the complex phenomena of multiliteracy and L2 monoliteracy, and how they influence the bond between research and policy. Interviews with a range of scholars whose first language is not English reveal that if they aspire to the career returns that membership of the global academic elite offers, not only do their local languages (except a handful of super-central languages) have negligible career value, and frequently no audience for their specialization, technical vocabulary, which may have been created in English and not translated, is also often lacking. Moreover, unlike English, because journals in those languages assume a fully fluent native-speaker audience that values stylistic complexity, they expect authors to write with more elegance than they would be in English, a language they may well have been trained to write in academically, unlike their first language. The cumulative effect of greater linguistic effort for diminishing career returns helps explain why many of the younger scholars I interviewed do not write in their first language.

Striving for professional success, these scholars are motivated to move towards the center and away from the periphery. This mobility has two consequences: first it contributes to the emergence of an overarching global academic community, communicating with each other and sharing research in IIJs through the medium of English - those I call the international academic elite-co-existing with a collection of local academic communities, not extensively in communication either with the global community or with each other, often perceived (A5, A7) as second rate. Especially for young researchers whose first language is not a super-central language [16], and who seek a successful academic career, there is every benefit in being connected to this global academic elite, and little or none in being connected to the community of the national language, especially when the national language policy in question may offer greater rewards for publication in English, as discussed above.

In 2000, in a public lecture on language policy in the European Union, the Dutch sociologist de Swaan [16] noted the tendency for political debates and political culture in the European Union to occur at national level and to be isolated from each other, with forces that mitigate against "intellectuals who might aspire to transcend the borders of nation." In linking the concept of the European democratic deficit to language, de Swaan [16] argued that the absence of a common linguistic space constrains such debates to the national level. This is not wrong. What I argue here is that the intellectual sphere, which can and should inform and influence policy and politics, does already "transcend the borders of nation" through English. Yet it is not enough for democracy to have a European (or world) space in English on the intellectual level if it does not intermesh effectively with national socio-political communities that function in the local language. de Swaan is right that "intellectuals who...aspire to transcend the borders of nation" run a risk; it is not a personal risk, however, but a risk to the nations they dissociate themselves from [16]. When the most promising young scholars disengage from local academe and from local societal contribution because not only the nature of publishing in the academic world, but also ill-thought-through policies encourage them to do so for career gains, transcending borders brings no benefit to the nation but only to the individual.

How then can national governments or universities, where the decision is theirs, act to ensure communication between the global and the local? First, at the level of teaching, it is important that prospective scholars are taught writing both in their native language and in English, and preferably in the former first, for a variety of practical, psychological and cultural reasons [17]. This in turn entails that written assignments that involve and develop argumentative and analytical skills are set in the first language, so that students have ample chance to practice these. Although much literature will need to be read in English, the value of local knowledge and research in solving local problems should be emphasized where possible. As one trilingual young scholar in group B commented:

I don't really publish in my other languages, but what I do do is when I write an article in English I make sure I read and incorporate all the relevant literature that's available in my other languages. I think that's very important. (B5) 
Second, while university and national policies would be ill advised to stop incentivizing publications in international highimpact journals $[3,7,10,12]$ rewards and incentives need to be constructed and adequately weighted so that those who write both academically for the international community and locally in the genres of policy debates and other outreach areas are rewarded more than those who write only for international research or only for the local community. The application of academic knowledge to local contexts and audiences will be most effective if it is recognized as important by young scholars from the beginning of their career. While it is beyond the scope of this article to elaborate the details of such a system, clearly some reward for outreach writing will have a more positive impact than none at all.

An international English-writing academic elite, like Huntington's Davos Culture, risks becoming disengaged from the vast majority of the world's population if it does not interact with national and local communities. Multiliterate scholars can, do, and should do this. And if they cease to do it because universities and education ministries institute policies that fail to recognize that both the creation of knowledge and its application to specific contexts are valuable academic activities to be encouraged and rewarded, the consequences for society are not positive.

\section{Conflict of Interest}

No potential conflict of interest relevant to this article was reported.

\section{References}

1. Huntington SP. The clash of civilizations and the remaking of world order. New York, NY: Simon and Schuster; 1996.

2. Flowerdew J. Scholarly writers who use English as an additional language: what can Goffman's "stigma” tell us? J Engl Acad Purp 2008;7:77-86. https://doi.org/10.1016/ j.jeap.2008.03.002

3. Ge M. English writing for international publication in the age of globalization: practices and perceptions of mainland Chinese academics in the humanities and social sciences. Publications 2015;3:43-64. https://doi.org/10.3390/ publications 3020043

4. Lillis TM, Curry MJ. Academic writing in a global context: the politics and practices of publishing in English. London: Routledge; 2010.

5. Curry MJ, Lillis T. Introduction to the thematic issue: par- ticipating in academic publishing-consequences of linguistic policies and practices. Lang Policy 2013;12:209-13. https://doi.org/10.1007/s10993-013-9286-7

6. Biswas AK, Kirchherr J. Prof, no one is reading you. The Straits Times [Internet]. 2015 May 20 [cited 2017 Apr 18]. Available from: http://www.straitstimes.com/opinion/ prof-no-one-is-reading-you

7. Scholler D, Lips F, Lowik S, Wijnen A, Wakkee I. IXA valorisation guide. Amsterdam: Innovation Exchange Amsterdam; 2015.

8. de Swaan A. Words of the world: the global language system. Cambridge, UK: Polity Press; 2001.

9. Truchot C. Key aspects of the use of English in Europe. Unpublished report, Directorate General IV. Strasbourg: Council of Europe; 2002.

10. Lee H, Lee K. Publish (in international indexed journals) or perish: neoliberal ideology in a Korean university. Lang Policy 2013;12:215-30. https://doi.org/10.1007/s10993012-9267-2

11. FGBNU. Federal target program "Research and development on priority directions of scientific-technological complex of Russia for 2014-2020" [Internet]. Moscow: FGBNU; 2013 [cited 2017 Apr 18]. Available from: http:// fcpir.ru/upload/medialibrary/332/tekst-programmy.pdf

12. Muresan LM, Perez-Llantada C. English for research publication and dissemination in bi-/multiliterate environments: the case of Romanian academics. J Engl Acad Purp 2014;13:53-64. https://doi.org/10.1016/j.jeap.2013.10.009

13. Anderson L. Publishing strategies of young, highly mobile academics: the question of language in the European context. Lang Policy 2013;12:273-88. https://doi.org/10.1007/ s10993-013-9272-0

14. Duszak A. Looking globally, seeing locally: exploring some myths of globalisation in academia. Rev Canar Estud Ingl 2006;(53):35-46.

15. Duszak A, Lewkowicz J. Publishing academic texts in English: a Polish perspective. J Engl Acad Purp 2008;7:108-20. https://doi.org/10.1016/j.jeap.2008.03.001

16. de Swaan A. Why this is in English (and not in German, nor in Dutch): Schuman lecture 2000 [Internet]. Maastricht: Studium Generale; 2000 [cited 2017 Apr 18] Available from: http://deswaan.com/why-is-this-in-englishand-not-in-german-nor-in-dutch/

17. Bocanegra-Valle A. 'English is my default academic language': voices from LSP scholars publishing in a multilingual journal. J Engl Acad Purp 2014;13:65-77. https://doi. org/10.1016/j.jeap.2013.10.010 


\section{Appendix 1. Questions for interview}

In which languages do you sometimes or regularly write for publication? Which languages do you write more/less in? Have the languages you write in changed over time? How? What factors help you decide what language to write in? (prompts: audience? topic? purpose?)

Do you write different kinds of text or for different audiences in different languages?

Do you write differently in different languages? How does the chosen language affect the way you write?

If you don't write in your first language, why not?
Appendix 2. Questions for questionnaire

In which languages do you sometimes or regularly write for publication? Which languages do you write more/less in? Do you write different kinds of text or for different audiences in different languages?

What factors help you decide what language to write in? (prompts: audience? topic? purpose?)

Do you think it is important for academics to write in their first language? 